\title{
TRANSCRANIAL SONOGRAPHY IN MOVEMENT DISORDERS
}

\author{
Petra Bartova ${ }^{\mathrm{a}}$, David Skoloudik ${ }^{\mathrm{a}, \mathrm{c}}$, Michal Bar ${ }^{\mathrm{a}}$, Pavel Ressner ${ }^{\mathrm{b}}$, Petr Hlustik ${ }^{\mathrm{c}}$, Roman Herzig ${ }^{\mathrm{c}}$, \\ Petr Kanovskyc
}

a Department of Neurology, University Hospital, Ostrava, Czech Republic

${ }^{b}$ Department of Neurology, Hospital Novy Jicin, Czech Republic

c Department of Neurology, University Hospital and Medical School Olomouc, Czech Republic

e-mail: petrabartova@seznam.cz

Received: July 10, 2008; Accepted: August 18, 2008

Key words: Transcranial sonography/Substantia nigra/Parkinson's disease/Multiple-system atrophy/Corticobasal degeneration/Progressive supranuclear palsy/Huntington's disease/Dystonia/Essential tremor/Vascular parkinsonism/Spinocerebellar ataxia/Restless Leg syndrome/Dementia with Lewy bodies/Wilson's disease/

Background: Transcranial sonography (TCS) in the B-mode has the ability to image, infratentorial and supratentorial brain structures. For this reason, it has potential use in the diagnosis and differential diagnosis of various intracranial pathologies.

Methods and Results: The authors reviewed the contribution of TCS to the differentiation of a number of neurodegenerative diseases: in parkinsonian syndromes, TCS can evaluate echogenicity changes in specific structures such as the hyperechogenic area of the substantia nigra (SN) in Parkinson's disease and the hyperechogenic caudate nucleus in Huntington's disease as well as the hyperechogenic lentiform nucleus (LN) in dystonia and Wilson's disease. In parkinson-plus syndromes, TCS may detect changes in width of the third ventricle and of the frontal horns of the lateral ventricle. The hyperechogenic SN can also be used in healthy populations as a marker of subclinical injury to the nigrostriatal system.

Conclusion: TCS is a quick, safe and non-invasive method. It could be helpful in differentiation between several movement disorders together with clinical examination and other neuroimaging methods.

\section{INTRODUCTION}

The differentiation between idiopathic Parkinson's disease (PD) and atypical parkinsonian syndromes can be difficult especially at the beginning of the disease. A diagnosis of PD is based on clinical symptoms (UK Brain Bank criteria) and response to L-DOPA treatment ${ }^{1}$. Available neuroimaging methods such as computer tomography (CT) and magnetic resonance (MR) may detect structural abnormalities of the brain and contribute to differential diagnosis of parkinsonian syndromes. However, they often report normal findings, especially in the early stages of the disease. Moreover, the severity of the disease lacks an imaging correlate ${ }^{2}$.

Other neuroimaging methods such as single photon emission tomography (SPECT) and positron emission tomography (PET) identify biochemical changes in the nigrostriatal system and may detect a decrease in dopaminergic cells in the $\mathrm{SN}^{3-6}$. However, these techniques are very expensive and not widely accessible.

Transcranial sonography (TCS) on the other hand, is a neuroimaging method with the ability to provide data on various brain structures in its B-mode ${ }^{7-9}$. In addition, transcranial color-coded duplex sonography is able to provide information on the intracranial arteries and veins as well $1^{7,8}$. It is very quick, safe and non-invasive. The main limitation is that some patients do not have a sufficient bone window ${ }^{7,8}$. Although TCS resolution is inferior to MR, it can detect mesencephalic nuclei, assess the width of the third ventricle and the frontal horns of lateral ventricles. TCS could help in the differential diagnosis of PD and atypical parkinsonian syndromes (APS) in addition to clinical examination and other paraclinical, neuroimaging and genetic methods ${ }^{7,8}$.

\section{Transcranial sonography evaluation - methods}

TCS evaluation of brain structures is realized through a transcranial (preauricular) acoustic window using transcranial duplex probe with the frequency about $1-4 \mathrm{MHz}$, dynamic range is $50-170 \mathrm{~dB}$. Penetration depth is 14$16 \mathrm{~cm}$ with the imaging of the contralateral bone. TCS allows the depiction of brain structures in detail, e.g., mesencephalon with the zoom (Figure 1). Axial resolution of TCS evaluation is about $0.5-1.0 \mathrm{~mm}$, lateral resolution is about $3.0 \mathrm{~mm}$. The main limitation of TCS evaluation is insufficient transtemporal window, which is missing in $8-20 \%$ of patients, depending on age and $\operatorname{sex}^{8-12}$. There is also a dependency on examiner's skills $7,8,13$.

In May 2004, at the $9^{\text {th }}$ Meeting of ESNCH (European Society of Neurosonology and Cerebral Hemodynamics) a standardized procedure for TCS in neurodegenerative diseases was approved as mentioned by Water et al. ${ }^{7}$. 
Table 1. Transcranial Sonography Studies in Parkinsonism ${ }^{7}$

\begin{tabular}{|c|c|c|c|c|c|c|c|c|}
\hline Authors & $\begin{array}{c}\text { PD } \\
\text { Patients }\end{array}$ & $\begin{array}{l}\text { Healthy } \\
\text { Controls }\end{array}$ & $\begin{array}{c}\text { APS } \\
\text { Patients }\end{array}$ & $\begin{array}{l}\text { UPDRS III } \\
\text { (SD) }\end{array}$ & $\mathrm{Se} \%$ & $\mathrm{Sp} \%$ & PPV & NPV \\
\hline \multicolumn{9}{|c|}{ Studies comparing PD to controls } \\
\hline Becker et al. $(1995)^{9}$ & 30 & 30 & - & $27.7(13.1) \dagger$ & 40 & 100 & - & - \\
\hline Walter et al. $(2002)^{11}$ & 30 & 30 & - & $35.7(19.7)$ & 100 & 88 & - & - \\
\hline Ruprecht et al. $(2003)^{22}$ & 14 & 582 & - & - & 92 & 55.10 & 0.33 & 0.97 \\
\hline Walter et al. $(2004)^{58}$ & 7 & 73 & - & $39.1(20.5)$ & 100 & 28.50 & 0.58 & 1.0 \\
\hline \multicolumn{9}{|c|}{ Studies comparing PD to APS } \\
\hline Walter et al. $(2003)^{36}$ & 25 & - & $\begin{array}{c}16 \text { MSA } \\
9 \text { PSP }\end{array}$ & $\begin{array}{l}28.7(14.5) \\
36.3(16.6)^{*} \\
56.5(19)^{*}\end{array}$ & 91 & 96 & - & - \\
\hline Behnke et al. $(2005)^{35}$ & 102 & - & $\begin{array}{c}34 \text { MSA } \\
21 \text { PSP }\end{array}$ & - & - & - & $\begin{array}{c}0.964 \\
0.95\end{array}$ & - \\
\hline \multicolumn{9}{|c|}{ Studies comparing PSP and CBD } \\
\hline Walter et al. $(2004)^{39}$ & - & - & $\begin{array}{l}13 \mathrm{PSP} \\
8 \mathrm{CBD}\end{array}$ & $\begin{array}{l}43.5(20.1)^{*} \\
39.8(24.6)^{*}\end{array}$ & 88 & 100 & - & - \\
\hline \multicolumn{9}{|c|}{ Studies within the PD-group, without controls } \\
\hline Berg et al. $(2001)^{10}$ & 112 & - & - & $16 \dagger$ & 91 & & - & - \\
\hline Berg et al. $(2005)^{59}$ & 16 & - & - & $\begin{array}{l}16(10) \\
26(10) \#\end{array}$ & 81 & & - & - \\
\hline
\end{tabular}

\section{Footnotes}

$\dagger$ - Columbia University Rating Scale (SD), * - severity of APS, \# - at five years follow up, - - not stated, not applicable

Table 2. Evaluation of echogenicity of substantia nigra using transcranial sonography

\begin{tabular}{|l|l|}
\hline & Echogenicity \\
\hline Grade I & The same echogenicity as brainstem \\
\hline Grade II & Very low but clearly detectable area of substantia nigra \\
\hline Grade III & Medium echogenicity, lower than perimesencephalic cisterns \\
\hline Grade IV & The same echogenicity as perimesencephalic cisterns \\
\hline Grade V & Higher echogenicity than perimesencephalic cisterns \\
\hline
\end{tabular}

TCS evaluation substantia nigra in Parkinson's disease

In patients with PD, TCS is able to detect a hyperechogenic and enlarged area of the $\mathrm{SN}$ as a marker of striatonigral damage. It has a sensitivity of about $90 \%$ and specificity of about $90 \%$ (ref. ${ }^{14-18}$ ) - see Table 1 .

The first evaluations of the substantia nigra in PD patients were published in 1995. Becker et al. described
SN in idiopathic PD as an echogenic nucleus inside the anechogenic butterfly mesencephalon (Fig. 2) through the transtemporal window. They assessed ${ }^{9}$ the area of the hyperechogenic SN nucleus and set up a threshold for pathological area of $\mathrm{SN}$ at $\geq 0.19 \mathrm{~cm}^{2}$.

The following study of Walter et al. estimated the upper limit of the normal area of the hyperechogenic SN 


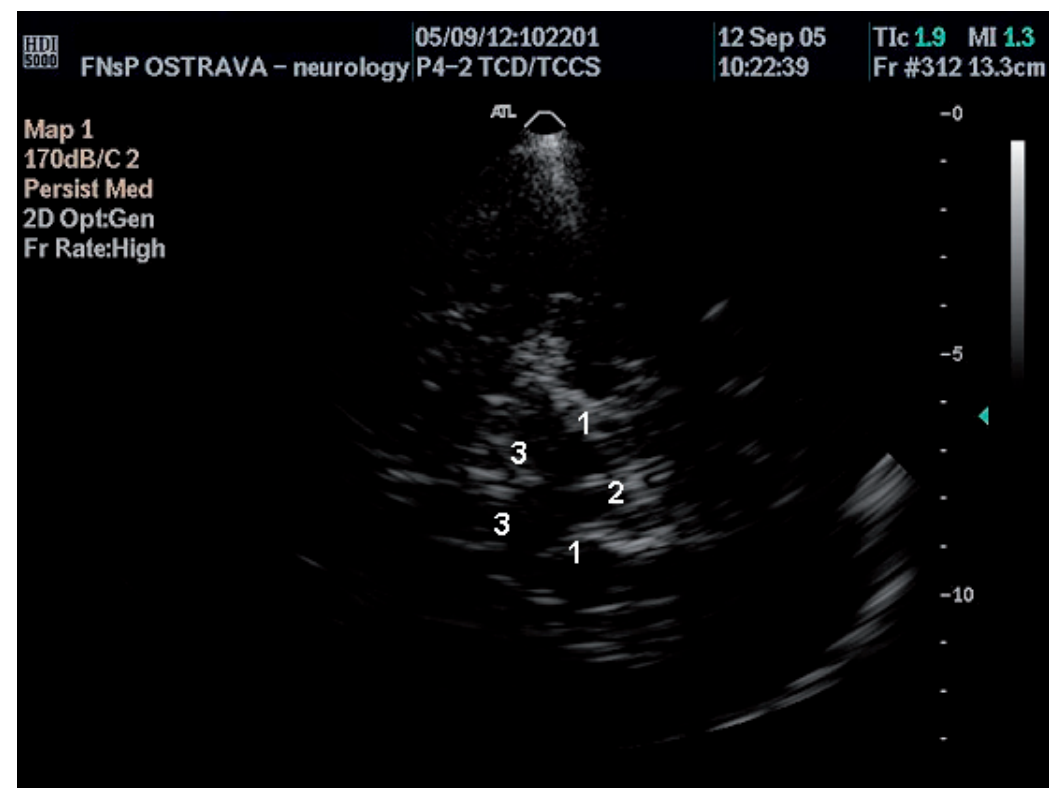

Fig. 1. Transcranial sonography: mesencephalon with normal finding of substantia nigra - Grade II.

1 - Mesencephalon, 2 - Fourth ventricle, 3 - Substantia nigra

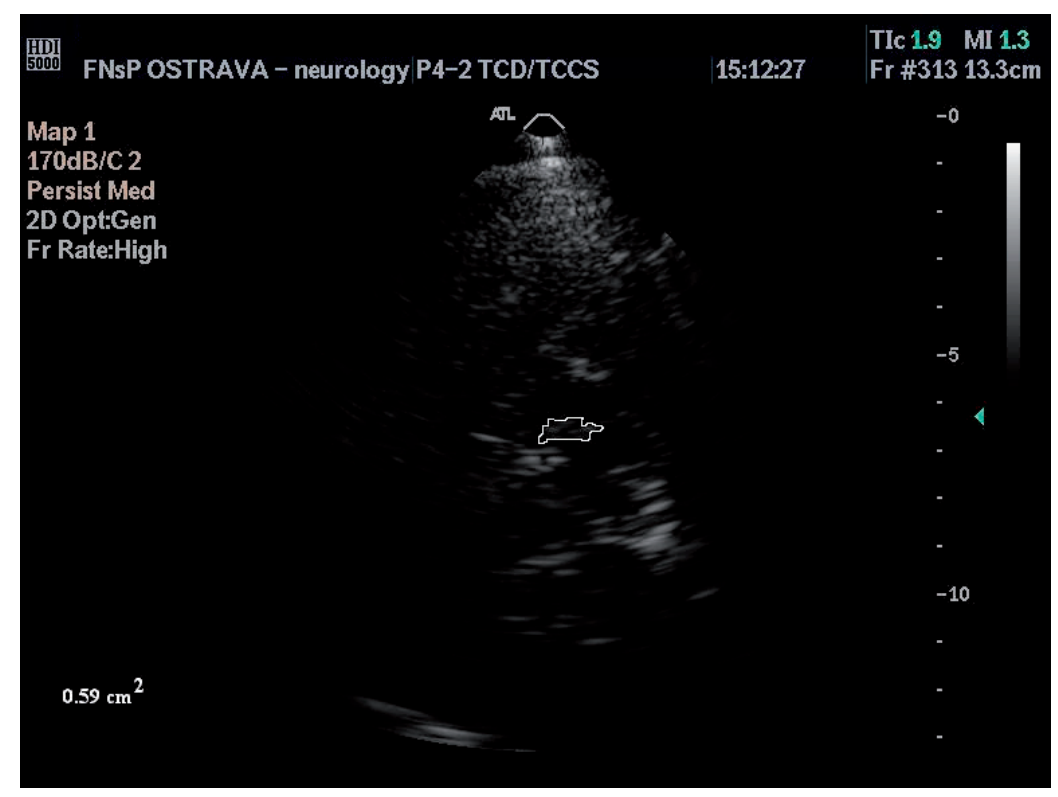

Fig. 2. Transcranial sonography: hyperechogenic enlarged substantia nigra - Grade III, $0.59 \mathrm{~cm}^{2}$.

$\leq 0.20 \mathrm{~cm}^{2}$, whereas an area of $\mathrm{SN} \geq 0.25 \mathrm{~cm}^{2}$ was assessed as pathological.

An area of $\mathrm{SN}$ between 0.20 and $0.25 \mathrm{~cm}^{2}$ was assessed as a borderline value ${ }^{11}$.

The second possibility of TCS is in evaluating echogenicity of SN on a five-grade scale ${ }^{12}$ - Table 2 . Echogenicity SN higher than grade II and area $\geq 0.25 \mathrm{~cm}^{2}$ was considered pathological. In our study, we evaluated the area and echogenicity of SN in 111 patients of PD. A hyperechogenic $\mathrm{SN}$ grade more than II and area $\geq 0.25 \mathrm{~cm}$ were detected in $84.7 \%$ of PD patients ${ }^{19}$.

Berg et al. studied ${ }^{6}$ the relationship between SN echogenicity and motor symptoms in an elderly population
(56-70 years). They evaluated 330 patients and concluded that a hyperechogenic SN was often connected with bradykinesia, rigidity and higher age (over 60). We obtained very similar results in our study in a group of 202 patients with movement disorders. Hyperechogenic and enlarged area of SN were significantly more frequent in patients with symmetrical bradykinesia and rigidity ${ }^{20}$. A subsequent study showed that a hyperechogenic $\mathrm{SN}$ is enlarged contralaterally to manifest parkinsonian symptoms ${ }^{21}$.

However, in 8-10 \% of healthy subjects, a hyperechogenic SN can be detected. Recent ${ }^{18} \mathrm{~F}$-DOPA ( ${ }^{18} \mathrm{~F}$-fluorodopa) PET studies have revealed a marked decrease in 
the accumulation of ${ }^{18} \mathrm{~F}$-DOPA in the sample studied. Although the examination of motor function was normal, it was suspected that there was a subclinical alteration of the striatonigral system ${ }^{6,10,15,21}$.

Walter et al. ${ }^{11}$ investigated a group of patients with idiopathic PD and patients with non extrapyramidal symptoms. The results of the study show that bilaterally enlarged hyperechogenic $\mathrm{SN}$ is probably a marker of idiopathic PD. A hyperechogenic SN was detected in $45 \%$ of the relatives of patients with idiopathic $\mathrm{PD}^{22}$. Moreover, in asymptomatic subjects with the Parkin mutation, a correlation was found between enlarged hyperechogenic SN and striatonigral alterations in PET studies ${ }^{23}$.

Subsequent work detected a hyperechogenic SN in patients with olfactory dysfunction together with dopamine reuptake alteration on SPECT (123-FP-CIT) in $70 \%$ of examined patients ${ }^{23}$.

\section{Unipolar depression in Parkinson's disease}

Depression and anxiety are very frequent symptoms in PD with a prevalence of about $40 \%$. They are probably related to the role of the brainstem in regulating mood and cognition. Becker et al. evaluated brainstem changes in patients with PD and unipolar depression using TCS ${ }^{24}$. These patients have significantly decreased echogenicity of the brainstem raphé nucleus in comparison with non-depressive PD patients and a control group. There were also correlations with signal decrease on $\mathrm{T}_{2} /$ diffusion-weighted images in MR studies ${ }^{24}$. Echogenicity inside the brainstem included nuclei and tracts, which connect mesencephalic structures with nuclei in the dorsocaudal (basal) limbic system. Morphologic alteration in the basal limbic system is one of the pathological factors in depression ${ }^{26}$.

\section{Parkinsonian syndrome induced by neuroleptic therapy}

Berg et al. ${ }^{27}$ measured area and echogenicity of SN in patients with a parkinsonian syndrome induced by neuroleptic therapy use in psychiatric indications in a retrospective study. In patients with a neuroleptic-induced parkinsonian syndrome, SN was significantly enlarged $\left(0.19 \mathrm{~cm}^{2}\right.$ on the right side and $0.21 \mathrm{~cm}^{2}$ on the left side), compared to neuroleptic-treated patients without parkinsonian symptoms $\left(0.12 \mathrm{~cm}^{2}\right.$ on the right side and 0.11 $\mathrm{cm}^{2}$ on the left side). The pathological mechanism underlying expression of parkinsonian symptoms in these patients is probably neuroleptic blockade of dopaminergic receptors in the basal ganglia. According to a published hypothesis, it could manifest more frequently in patients with subclinical injury to the basal ganglia. The size of hyperechogenic $\mathrm{SN}$ is associated with severity of extrapyramidal symptoms ${ }^{27}$.

\section{Echogenicity of substantia nigra and iron metabolism}

The exact reason for the hyperechogenicity and enlargement of $\mathrm{SN}$ in PD and parkinsonian syndromes is still unknown. Post-mortem assessment demonstrate that echogenicity of SN could relate to increased iron deposits in the basal ganglia ${ }^{15}$. Berg et al. in their experimental study attempted to confirm this hypothesis. The rat brain was evaluated using TCS after stereotactic injection of different concentrations of iron or ferritin, zinc and 6-OHDA (6-OH-dopamine) together with desferrioxamine. The iron content in the SN was assessed using spectroscopy and the echogenicity of SN was measured as well. Increasing iron content increased the echogenicity of $\mathrm{SN}^{14}$.

It is possible that a hyperechogenic and enlarged $\mathrm{SN}$ in atypical syndromes like MSA (multiple system atrophy) and VP (vascular parkinsonism) is caused by this mechanism. Reasons for development of variable iron metabolism impairments in these parkinsonian syndromes will be the topic of further research ${ }^{14}$. Neuronal degeneration in the $\mathrm{SN}$ region could also be induced by toxic exposure to pesticides, heavy metals, by basal ganglia injury or by oxidative damage ${ }^{5,14}$. The authors speculate about the possible contribution of pure SN atrophy ${ }^{19}$.

Iron participates in various biological processes. It is an essential cofactor of many enzymes. Iron supports the transport of oxygen in hemoglobin and plays the main role in many oxidative and reduction processes as a cofactor. On the other hand, free iron in the human body is toxic given its ability to form free radicals. Ferrous ion $\mathrm{Fe}^{++}$can generate the highly toxic hydroxyl and superoxide free radicals or molecular oxygen ${ }^{28}$.

Ferritin is a storage protein of iron in the tissues and is important for blood formation. It is present in the normal axon. Recent studies reported on two cases of $L$-ferritin gene mutations. These mutations are associated with degeneration of the basal ganglia and occur in families. The disorder is termed hereditary ferritinopathy. The first published work failed to confirm more frequent occurrence of these mutations in patients with PD or increased SN echogenicity $^{29}$.

Ferroxidase ceruloplasmin $(\mathrm{Cp})$ is involved in iron metabolism. It is produced by the spleen and secreted into the blood. By oxidizing the ferrous $\mathrm{Fe}^{++}$form of iron to the ferric $\mathrm{Fe}^{+++}$form, $\mathrm{Cp}$ promotes iron loading onto transferrin. In this way, $\mathrm{Cp}$ is an effective antioxidant and prevents oxidative damage to proteins, lipids and DNA. $\mathrm{Cp}$ is also produced by astrocytes in the brain, cerebellum, retina and epithelial cells of the choroid plexus. Astrocytes produce a special form of ceruloplasmin, which is connected to the membrane by glycosylphosphatidylinositol (GPI). This form of $\mathrm{Cp}$ plays a very important role in iron homeostasis and antioxidant processes in the brain.

Studies of patients with aceruloplasminemia, who have hereditary ceruloplasmin gene mutation, show that in these patients, iron accumulates in various organs, e.g., liver and brain. Iron deposits lead to neurodegeneration and expression of neurological symptoms - motor incoordination, parkinsonism, dementia and other medical disorders, such as diabetes mellitus.

Hochstrasser et al. ${ }^{30}$ examined mutation of $\mathrm{Cp}$ gen in 176 PD patients. D554E with I63T mutation was found in PD patients with hyperechogenic SN, whereas R793H mutation was also detected in the normal population with a hyperechogenic SN. Furthermore, this study shows a correlation of $\mathrm{Cp}$ and formation of Lewy bodies. Pilot 
study shows the possibility of correlation of $\mathrm{Cp}$ ferroxidase in blood and hyperechogenic $\mathrm{SN}^{31}$.

Neuromelanin is accumulated in $\mathrm{SN}$ pigmented neurons with normal aging. Neuromelanin plays an important protective role in inactivation of $\mathrm{Fe}^{++}$and reduced formation of free hydroxyl radicals, which otherwise contribute to oxidative stress and neuronal death. Neuromelanin could interact with many heavy metal ions, e.g., zinc, copper, manganese or cadmium. In the course of Parkinson's disease and related syndromes, the concentration of iron in the SN increases by $30-35 \%$ (ref. ${ }^{32}$ ). In contrast, neuromelanin in SN is decreased in PD patients. This decrease could be caused by reduction of neuromelanin production or its higher degradation or higher sensitivity of pigmented neurons to neurotoxins ${ }^{53}$. Zecca et al. in post-mortem studies detected increased content of iron in the hyperechogenic SN in 40 PD patients. A negative correlation was found between hyperechogenic SN and neuromelanin content of $\mathrm{SN}^{33,34}$.

Although the exact mechanism by which iron gets redistributed in various region of the brain is poorly understood, it is known that brain cells in certain areas of the brain have variable ability of to accumulate iron. It has not been clarified whether this accumulation is caused by primary accumulation of iron compounds in microglia and macrophages or by iron accumulation in neurons ${ }^{28}$.

\section{TCS evaluation in other movement disorders}

Studies published so far demonstrate that changes in SN echogenicity detected by TCS are not specific for $\mathrm{PD}$, but they are also more frequent in other movement disorders than in a healthy population ${ }^{7,8,18}$. In addition to the SN structure, TCS can be used to evaluate changes in others structures - e.g., the lenticular nucleus, caudate nucleus, cerebellum, width of the third ventricle or the frontal horn of lateral ventricles (Table 2).

\section{Multiple system atrophy, progressive supranuclear palsy and corticobasal degeneration}

Enlarged and hyperechogenic SN on TCS examination is not specific to PD. In patients with multiple system atrophy (MSA), increased echogenicity and area of SN is also seen. Behnke et al found hyperechogenic SN in $25 \%$ patients with MSA and medium echogenicity in another $37.5 \%$ (ref. $^{35,36}$ ). In our group of patients with MSA, hyperechogenic SN (> grade III) was detected in $42.9 \%$ and medium echogenic (grade III) in $14.2 \%$ patients. Enlarged area of $\mathrm{SN} \geq 0.25 \mathrm{~cm}^{2}$ was found in $50 \%$ patients ${ }^{19,20}$. Patients were selected using Quinn's criteria ${ }^{37,38}$.

Between $72 \%$ and $82 \%$ of patients with MSA also have a hyperechogenic lenticular nucleus ${ }^{35,36}$. Very similar findings were described in patients with progressive supranuclear palsy (PSP) ${ }^{7,39}$. Smaller studies reported that echogenicity of SN and lenticular nucleus could distinguish PN from MSA and PSP in more than $90 \%$ (ref. ${ }^{7}$ $\left.{ }^{35,36}\right)$. Signal decrease in globus pallidus on $\mathrm{T}_{2}$-weighed MR images also correlates with a hyperechogenic LN on $\mathrm{TCS}^{39}$. Measurement of third ventricle could be used in differential diagnosis between MSA and PSP. In the majority of the patients with PSP, the third ventricle was dilated by over $10 \mathrm{~mm}$. Using this measurement, we could distinguish also PSP and corticobasal degeneration (CDB) in $90 \%$ (ref. ${ }^{39}$ ), especially if combined with a bilaterally enlarged hyperechogenic SN, which occurs in $90 \%$ patients with $\mathrm{CBD}^{39}$.

\section{Essential tremor}

Differentiation between PD and essential tremor (ET) based on clinical examination can be difficult at the beginning of the disease ${ }^{40}$. Niehaus et al. ${ }^{41}$ in a pilot study demonstrate that echogenicity of SN in ET is significantly lower than in patients with PD and is very similar to the findings in a healthy population. Hyperechogenic enlarged SN was detected in 28 (93\%) of 30 patients with tremor-dominant PD, but only in 2 patients (10\%) with ET. The authors found very similar results in their study. Hyperechogenic and enlarged SN were detected in $20 \%$ patients with $\mathrm{ET}^{19}$.

Stockner et al. (2007) studied the occurrence of hyperechogenic SN in ET patients as a marker of future development of PD. Sixteen percent of 44 ET patients had an hyperechogenic $\mathrm{SN}$ in comparison to $3 \%$ patients in the control group (3\%) and $100 \%$ PD patients ${ }^{42}$.

\section{Wilson's disease}

Wilson's disease is an autosomal recessive hereditary disease in which copper becomes abnormally stored especially in hepatic tissue, cornea and basal ganglia. Hepatal, neurological and psychiatric symptoms may manifest. In 2005, Walter et al. investigated 21 patients with Wilson's disease, out of whom 18 patients had neurological symptoms and 3 patients were neurological symptom free. Hyperechogenic SN was detected in $10 / 21$ patients. This finding did not correlate with the expression and severity of neurological symptoms. In 19 patients, they detected hyperechogenic LN, in 12 out of these patients this pathology was also visible on MRI. A hyperechogenic thalamus was detected in 9 patients, enlargement of the third ventricle in 4 patients, enlargement of frontal horns of lateral ventricles in 5 patients. Hyperechogenic LN and thalamus correlated with expression and disease severity ${ }^{43}$.

The results of the pilot studies suggest the ability of TCS to detect accumulation of copper in the basal ganglia preclinically but the results must be confirmed in larger patient population $^{43}$.

\section{Vascular parkinsonism}

Tsai et al. (2007) studied hyperechogenic SN in 80 patients with $\mathrm{PD}$ in comparison with 30 patients with vascular parkinsonism (VP) and 60 normal controls. A hyperechogenic SN was present in $84 \%$ of PD patients, in $20 \%$ of VP patients and in $5 \%$ of controls. $66.7 \%$ of VP patients had evident vascular changes on TCS evaluation and their pulsatility index was significantly higher than in PD patients and controls. There were no significant differences in flow velocities between the VP and PD patients and controls ${ }^{44}$.

In our pilot work $^{19}$, we evaluated 11 patients with 
VP using TCS. Patients were classified according to the vascular rating scale for the diagnosis of vascular parkinsonism $^{45,46}$. Echogenicity and area of SN were higher in comparison with healthy population, but the results did not reach statistical significance. Hyperechogenic SN was detected in $18.2 \%$ of cases and medium echogenicity in $45.4 \%$.

\section{Dementia with Lewy bodies}

Idiopathic PD and dementia with Lewy bodies (DLBD) are both characterized neuropathologically by the presence of Lewy bodies in various parts of the brain, especially in the brainstem, diencephalon, basal ganglia and neocortex. The presence of Lewy bodies is the main pathological substrate underlying cognitive dysfunction in PD and DLBD. Neuroimaging methods such as CT, $\mathrm{MR}$ and PET are not able to distinguish idiopathic PD from DLBD.

Walter et al. studied echogenicity of $\mathrm{SN}$ in patients with DLBD, Parkinson's disease patients with dementia (PDD) and PD patients without dementia. Hyperechogenic enlarged SN was detected at least on one side in $97 \%$ patients with DLBD, $97 \%$ patients with PDD and $94 \%$ patients with PD without dementia. Bilateral hyperechogenic SN was detected mainly in DLBD in $80 \%$. Only one third of PD patients had bilateral findings of hyperechogenic SN. In PND patients these findings were associated with the youngest age. An asymmetry index was $\geq 1.15$.

PDD and DLBD patients could be discriminated by a combination of hyperechogenic enlarged SN, asymmetry index and onset age with a sensitivity of $96 \%$ and specificity of $80 \%$, positive predictive value was $93 \%$. In patients with DLBD and PDD the width of the third ventricle and frontal horn was significantly larger than for PD patients without dementia. This enlargement correlated with UPDRS scale in PDD ${ }^{47}$.

\section{Huntington's disease}

Huntington's chorea is a genetically caused neurodegenerative disease characterized by expansion of CAG triplets which leads to clinical symptoms. Postert et al. ${ }^{48}$ published the first results of TCS evaluation of patients with Huntington's disease in 1999. In $40 \%$ of their patients, a hyperechogenic SN (in $27 \%$ ) or caudate nucleus (in $13 \%$ ) was detected. No changes in the echogenicity of the thalamus or LN there were found. It is suspected that hyperechogenicity of the caudate nucleus is caused by gliosis or increase in metal concentration. Neuropathological studies have confirmed higher levels of iron and lower levels of ferritin in the caudate nucleus. Increase in copper concentration is probably responsible for the hyperechogenic $\mathrm{SN}^{49}$.

\section{Spinocerebellar ataxia}

The results of a recent TCS study ${ }^{50}$ confirm that patients with genetically-proven spinocerebellar ataxia subtype 3 (SCA3) show hyperechogenicity of various brain structures, as do subtypes SCA1 and SCA2. Hyperechogenic white matter of the cerebellum was de- tected in $57 \%$, hyperechogenic dentate nucleus in $54 \%$, hyperechogenic SN in $40 \%$, hyperechogenic putamen in $40 \%$ and hyperechogenic pallidum in $40 \%$ patients. These were significantly higher than in the healthy population ( $p<0.05)$. Moreover, cerebellar atrophy and enlargement of the fourth ventricle were detected in all patients with SCA3. Finally, the width of the third ventricle and the lateral ventricle were significantly larger than in the control group ${ }^{51}$.

\section{Dystonia}

Dystonia is characterized by involuntary prolonged muscle contractions that distort the body into typical postures $^{52,53}$. The pathogenesis of idiopathic dystonia and their origin is still unknown. It is known that the basal ganglia are the generator of dystonic movement. One of the pathological mechanisms described in the patients with idiopathic dystonia is increase in copper content in LN. Accumulation of copper probably causes disturbance of neuronal transfer from LN to motor cortex. The reason for copper metabolism impairment is unclear. Menkeson protein is the copper-transporting membrane ATP-ase and transports copper from cells outside. The results indicate that reduction of Menkeson protein gives rise to copper metabolism impairment and accumulation of copper in brain cells.

The first evaluation of dystonic patients using TCS were published by Naumann et al. in 1996 (ref. ${ }^{52}$ ). Subsequent studies ${ }^{53}$ demonstrated that hyperechogenic $\mathrm{LN}$ is present in patients with torticollis or dystonic writer's cramp on the contralateral side of rotation of the head or affected hand. This echogenicity is higher than in a normal population ${ }^{53}$. A hyperechogenic SN was found in patients with facial dystonia only in $31 \%$ (ref. ${ }^{52}$ ). In practice, hyperechogenic LN could support the diagnosis of idiopathic dystonia and differentiate tardive dyskinesia and psychogenic dystonia.

\section{Restless leg syndrome}

The majority of patients with restless leg syndrome (RLS) have normal neurological findings on clinical examination and routine neuroimaging ${ }^{54,55}$. MRI studies which are able to quantify the concentration of iron in the brain of patients with RLS (according to criteria from the year 2003) $)^{55}$, detected decrease of iron concentration in $\mathrm{SN}$ and putamen ${ }^{56}$.

Two TCS studies reported a reduction in SN echogenicity in $82 \%$ of patients with idiopathic RLS and 40 $\%$ with the secondary RLS. The detectable area ${ }^{56,57}$ of SN was less than $0.1 \mathrm{~cm}^{2}$. In both groups, the same pathological mechanism is suggested - iron homeostasis disorder in the brain ${ }^{56,57}$.

\section{Reproducibility of the sonographic evaluation}

Many studies have shown that TCS is a reliable method with high specificity and sensitivity in the diagnosis of $\mathrm{PD}^{14-18}$. Correlations of SN evaluation were statistically significant $(r=0.8 \text {, Cohen's kappa coefficient } 0.83)^{6,8}$.

Our study focused on the inter-reader reproducibility of TCS evaluation and correlations in the assessment of 
substantia nigra ( $\mathrm{SN}$ ) echogenicity and area measurement by physician-sonographer, sonographic lab assistant and physician without sonographic experience. Correlations between readers (intra-reader and inter-reader) and correlation between investigators (intra-investigator and interinvestigator) were assessed. Correlations between readers were $r=0.55-0.82$ for evaluation of echogenicity and $r=$ 0.31-0.74 for evaluation of SN area $(p<0.05)$.

Intra - reader correlations were significant only in an experienced sonographer $(r=0.85-0.96$ for echogenicity and $\mathrm{r}=0.51-0.69$ for area $\mathrm{SN}, \mathrm{p}<0.001)$.

Also all correlations between investigators (intra-investigator and inter-investigator) were significant as well for evaluation of area $(r=0.69-0.88$ and $r=0.5-0.61)$, as well as echogenicity SN ( $r=0.64-0.92$ and $r=0.51-0.69$, $\mathrm{p}<0.05)$. All 3 readers identified the same 15 patients with SN echogenicity III or more. It is known that semiquantitative TCS evaluation of area and echogenicity of SN depends on sonographer experience. Only an experienced sonographer is able to achieve reliable results with statistically significant correlations. Correlations between sonographic lab assistant and physician without sonographic experience were low ${ }^{13}$.

\section{CONCLUSION}

TCS is a very quick, non invasive and inexpensive examination method. It could be helpful in the differential diagnosis of movement disorders. The results depend on the examiner experience and quality of transtemporal bone window. Using TCS, we could also detect structural involvement of the nigrostriatal system in preclinical stages of other neurodegenerative disorders. Available pilot results of these observations are presently being replicated in wider patient populations.

\section{ABREVIATIONS}

APS - atypical parkinsonian syndromes

CBD - corticobasal degeneration

MSA - multiple system atrophy

NPV - negative predictive value

PD - Parkinson's disease

PPV - positive predictive value

PSP - progressive supranuclear palsy

SD - standard deviation

Se - sensitivity

Sp - specificity

TCS - transcranial sonography

UPDRS - Unified Parkinson's Disease Rating Scale

\section{REFERENCES}

1. Gelb DJ, Oliver E, Gilman S. Diagnostic criteria for Parkinson disease. Arch Neurol. 1999; 56:33-39.

2. Schrag A, Good CD, Miszkiel K, Morris HR, Mathias CJ, et al Differentiation of Atypical Parkinsonian Syndromes with Routine MRI. Neurology. 2000; 54:697-702.
3. Brucke T, Asenbaum S, Pirker W, Djamshidian S, Wenger S, et al. Measurement of the Dopaminergic Degeneration in Parkinson's Disease with [123I]-CIT and SPECT: Correlation with Clinical Findings and Comparison with Multiple System Atrophy and Progressive Supranuclear Palsy. J Neural Transmit. 1997; 50(Suppl.):9-24.

4. Booij J, Speelman JD, Horstink MWIM, Wolters EC. The Clinical Benefit of Imaging Striatal Dopamine Transporter with [123I]FP-CIT SPECT in Differentiating Patients with Presynaptic Parkinsonism from those with Other Forms of Parkinsonism. Eur J Nuclear Med. 2001; 28:266-272.

5. Asenbaum S, Pirker W, Angelberger P, Bencsits G, Pruckmayer M, et al. [123I]beta-CIT and SPECT in Essential Tremor and Parkinson's Disease. J Neural Transm. 1998; 105:1213-1228.

6. Berg D, Becker G, Zieler B, Tucha O, Hofman E, Preier M, et al. Vulnerability of the nigrostriatal system as detected by transcranial ultrasound. Neurology. 1999; 53:1026-1031.

7. Walter U, Behnke S, Eyding J, Niehaus L, Postert T, Seidel G, et al. Transcranial brain parenchyma sonography in movement disorders: State of the art. Ultrasound in Medicine and Biology. 2007; 33:1525.

8. Becker G, Berg D. Neuroimaging in basal ganglia disorders: perspectives for transcranial ultrasound. Movement Disorders. 2001; 16:23-32.

9. Becker G, Seufert J, Bogdahn U, Reichmann H, Reiners K. Degeneration of substantia nigra in chronic Parkinson's disease visualized by transcranial color-coded real-time sonography. Neurology. 1995; 45:182-184.

10. Berg D, Siefker Ch, Ruprecht -Dörfler P., Becker G. Relationship of substantia nigra echogenicity and motor function in elderly subjects. Neurology. 2001; 56:13-17.

11. Walter U, Wittstock M, Benecke R, Dressler D. Substantia nigra echogenicity is normal in non-extrapyramidal cerebral disorders but increase in Parkinson's disease. J Neural Transm. 2002; 109:191196.

12. Školoudík D, Škoda O, Bar M, Brozman M, Václavík D. Neurosonologie. Galén:Praha. 2003; 243-245.

13. Skoloudik D, Fadrna T, Bartová P., Langova K, Ressner P, Zapletalova O, Hlusik P, Herzig R, Kanovsky P. Reproducibility of sonographic measurement of the substantia nigra. Ultrasound Med Biol. 2007; 33:1347-1352.

14. Berg D, Grote C, Rausch WD, Maurer M, Wiesmann W, Reder P, et al. Iron accumulation of the substantia nigra in rats visualized by ultrasound. Ultrasound Med Biol. 1999; 25:901-904.

15. Berg D, Roggendorf W, Schroder U, Klein R, Tatschner T, et al. Echogenicity of Substantia Nigra, Association with increased iron content and marker for susceptibility to nigrostriatal injury. Arch Neurol. 2002; 59:999-1005.

16. Ressner P, Skoloudik D, Hustik P, Kanovsky P. Echogenicity of substantia nigra in Parkinson's disease - pilot study. J Neuroimaging. 2007; 17:164-167.

17. Ressner P, Školoudík D, Kaňovský P. Echogenita substantia nigra u Parkinsonovy nemoci - pilotní studie. Cesk Slov Neurol N. 2006; 102:376-379.

18. Constantinescu R, Ravina B, Berg D. Should transcranial sonography be used for the diagnosis of Parkinson's disease, controversy. Moving Along. Epub 2006:1205.

19. Bártová P, Školoudík D, Fadrná T, Ressner P, Bar M, Herzig R, Kaňovský P. Ultrazvukové hodnocení substantia nigra u pacientů s parkinsonskými syndromy, Česk Slov Neurol N 2007; 103:653657.

20. Bartova P, Skoloudik D, Fadrna T, Ressner P, Kanovsky P, Herzig R. Sonographic evaluation of substantia nigra in parkinsonian syndromes. Parkinsonism and Related disorders 2007; 13(Suppl 2): 123 .

21. Berg D, Siefker Ch, Becker G. Echogenicity of the substantia nigra in Parkinson's disease and its relation to clinical findings. J Neurol. 2001; 248:684-689.

22. Ruprecht-Dörfler P, Berg D, Tucha O, Benz P, Meier-Meitinger M, Alders GL, et al. Echogenicity of the substantia nigra in relatives of patients with sporadic Parkinson's disease. Neuro Image. 2003; 18:416-422. 
23. Semmer U, Hummel T, Cormann K, Mueller A, Frasnelli J, Kropp $\mathrm{J}$, et al. Detection of presymptomatic Parkinson's disease: combining smell tests, transcranial sonography and SPECT. Mov Disord. 2004; 19:1196-1202.

24. Berg D, Supprian T, Hofmann E, Zeiler B, Jäger A, Lange KW, et al. Depression in Parkinson's disease: brainstem midline alteration on transcranial sonography and magnetic resonance imaging. J Neurol. 1999; 246:1186-1193.

25. Becker G, Berg D, Lesch KP, Becker T. Basal limbic system alteration in major depression: a hypothesis supported by transcranial sonography and MRI findings. The Int J Neuropsychopharmacology. 2001; 4:21-31.

26. Becker T, Becker G, Seufert J, Hofmann E, Lange KW, et al. Parkinson's disease and depression: evidence for alteration of the basal limbic system detected by transcranial sonography. J Neurol Neurosurg Psychiatry. 1997; 63:590-595.

27. Berg D, Jabs B, Merschodorf U, Beckmann H, Becker G. Echogenicity of substantia Nigra Determined by Transcranial Ultrasound correlates with severity of parkinsonian symptoms induced by neuroleptic therapy. Biol Psychiatry. 2001; 50:463-467.

28. Rouault TA, Cooperman S. Brain Iron Metabolism. Semin Pediatr Neurol. 2006; 13:142-148.

29. Felletschin B, Bauer P, Walter U, Behnka S, Spiegel J, Csoti I, et al. Screening for mutations of the ferritin light and heavy genes in Parkinson's disease patients with hyperechogenicity of the substatnia nigra. Neuroscie Lett. 2003; 352:53-56.

30. Hochstrasser H, Baeur P, Walter U, Behnke S, Spiegel J, Csoti I, et al. Ceruloplasmin gene variations and substantia nigra hyperechogenicity in Parkinson disease. Neurology. 2004; 63:1912-1917.

31. Martinez-Heranndez R, Mountes S, Higuera-Callleja J, Rios C. Plasma ceruloplasmin ferroxidase activity cerrelates with substatnia nigra sonographic area in Parkinsons disease patients. Mov disord. 2007; 22(Suppl 1):640.

32. Salazar J, Mena N, Nunez MT. Iron dyshomeostasis in Parkinson's disease. J Neural Transm Suppl. 2006; 71:205-213.

33. Zecca L, D Tampellini, Gerlach M, Riederer P, Fariello RG, Schulzer D. Substantia nigra neuromelanin:structure, synthesis,and molecular behaviour. J Clin Mol Pathol. 2001; 54:414-418.

34. Zecca L, Berg D, Atzberger T, Ruprecht P, Rausch WD, Musico $\mathrm{M}$, et al. In vivo detection of iron and neuromelanin by transcranial sonography: a new aproach for early detection of substantia nigra damage. Mov Disord. 2005; 20:1278-1285.

35. Behnke S, Berg D, Naumann M, Becker G. Differentiation of Parkinson's disease and atypical parkinsonian syndromes by transcranial ultrasound. J Neurol Neurosurg Psychiatry. 2005; 76:423425.

36. Walter U, Niehaus L, Probst T, Benecke R, Meyer BU, Dressle D. Brain parenchyma sonography discriminates Parkinson's disease and atypical parkinsonian syndromes. Neurology. 2003; 60:74-77.

37. Gilman S, Low P, Quinn N, Albanese A, Ben-Shlomo Y, Fowler $\mathrm{C}$, et al. Consensus statement on the diagnosis of multiple system atrophy. American Autonomic Society and American Academy of Neurology. Clinical Auton Res. 1998; 8:359-362.

38. Růžička E, Roth J, Kaňovský P. Parkinsonova nemoc a parkinsonské syndromy. Praha: Galén. 2000; 118-165.

39. Walter U, Dressler D, Wolters A, Probst T, Grossmann A, Benecke R: Sonographic discrimination of corticobasal degeneration vs. Progressive supranuclear palsy. Neurology. 2004; 63:504-509.

40. Jankovic J. Essencial Tremor: clinical characteristics. Neurology. 2000; 54(Suppl 4):S21-S25.

41. Niehaus L, Savyer N, Weber U, Hertel R, Trottenberg T, Kupsch A. Brain parenchyma sonography in patients with essential tremor and Parkinson's disease. Cerebrovasc Dis. 2004; 17(Suppl 4):3.
42. Stockner H, Sojer M, Muler J, Wenning GK, Schmidauer C, Poewe W. Midbrain sonography in patients with essential tremor. Mov Disord. 2007; 22:414-417.

43. Walter U, Krolikowski K, Tarnacka B, Benecke R, Czlonkowska A, Dressler D: Sonographic detection of basal ganglia lesions in asymptomatic and symptomatic Wilson disease. Neurology. 2005; 64:1726-1732.

44. Tsai CF, Wu RM, Huang YW, Chen LL, Yip PK, Jeng JS: Transcranial color-coded sonography helps differentiation between idiopatic Parkinson's disease and vascular parkinsonism. J Neurol. 2007; 254:501-507.

45. Thanvi B, Lo N, Robinson T. Vascular parkinsonism - an important cause of parkinsonism in older people. Age and Ageing. 2005; 34:114-119.

46. Demirkiran M, Bozdemir H, Sarica Y. Vascular Parkinsonism: a distinct, heterogenous clinical entity. Acta Neurol Scand. 2001; 104:63-67.

47. Walter U, Dressler D, Wolters A, Wittstock M, Greim B, Benecke R. Sonographic discrimination of dementia with Lewy bodies and Parkinson's disease with dementia. J Neurol. 2006; 253:448-454.

48. Postert T, Lack B, Kuhn W, Jergas M, Andrich J, Braun B, et al. Basal ganglia alterations and brain atrophy in Huntington's disease depicted by transcranial real time sonography. J Neurol Neurosurg Psychiatry. 1999; 67:457-462.

49. Dexter DT, Jenner P, Scharpira AHV, Marsden CD. Alteration in levels of Iron, ferritin, and other trace metals in neurodegenerative diseases affecting the basal ganglia. Ann Neurol. 1992; 32(Suppl): S94-S100.

50. Postert T, Eyding J, Berg D, Przuntek H, Becker G, Flinger M, et al. Transcranial sonography in spinocerebellar ataxia type 3. J Neural Transm. 2004; 68(Suppl):123-133.

51. Dürr A, Stevanin G, Cancel G, Duyckaerts C, Abbas N, Didierjean $\mathrm{O}$, et al. Spinocerebellar ataxia 3 and Machado-Joseph disease. Clinical, molecular and neuropathological features. Ann Neurol. 1996; 39:490-499.

52. Naumann M, Becker G, Tokya KV, Supprian T, Reiners K. Lenticular nucleus lesion in idiopatic dystonia detected by transcranial sonography. Neurology. 1996; 47:1284-1290.

53. Becker G, Berg D, Francis M, Naumann M. Evidence for disturbances of copper metabolism in dystonia: From the image towards a new concept. Neurology. 2001; 57:2290-2294.

54. Allen RP, Barket PB, Wehr F, Song HK, Earley CJ. MRI measurement of brain iron in patients with restless legs syndrome. Neurology. 2001; 56:263-265.

55. Allen RP, Picchietti D, Hening WA, Trenkwalder C, Walters AS, Montplaisi J, et al. Restless legs syndrome: diagnostic criteria, special considerations, and epidemiology. A report from the restless legs syndrome diagnosis and epidemiology workshop at the National Institutes of Health. Sleep Med. 2003; 4:101-119.

56. Schmidauer C, Sojer M, Seppi K, Stockner H, Högl B, Biedermann $\mathrm{B}$, et al: Transcranial ultrasound shows nigral hypoechogenicity in restless legs syndrome. Ann Neurol. 2005; 58:630-634.

57. Godau J, Schweitzer KJ, Liepelt I, Gerloff Ch, Berg D. Substantia nigra hyperechogenicity: Definition and findings in restless legs syndrome. Mov Disod. 2007; 22:187-192.

58. Walter U, Klein C, Hilker R, Benecke R, Pramstaller PP, Dressler D. Brain parenchyma sonography detects preclinical parkinsonism. Mov Disord 2004; 19:1445-9.

59. Berg D, Schweitzer K, Leitner P, Zimprich A, Lichtner P, Belcredi P, et al. Type and frequency of mutations in the LRRK2 gene in familial and sporadic Parkinson's disease. Brain 2005; 128:3000-11. 